\title{
Microbial and dietary factors associated with the 8-prenylnaringenin producer phenotype: a dietary intervention trial with fifty healthy post-menopausal Caucasian women
}

\author{
Selin Bolca ${ }^{1,2}$, Sam Possemiers ${ }^{1}$, Veerle Maervoet ${ }^{1}$, Inge Huybrechts ${ }^{3}$, Arne Heyerick ${ }^{2}$, Stefaan Vervarcke ${ }^{4}$, \\ Herman Depypere ${ }^{5}$, Denis De Keukeleire ${ }^{2}$, Marc Bracke ${ }^{6}$, Stefaan De Henauw ${ }^{3}$, Willy Verstraete ${ }^{1}$ \\ and Tom Van de Wiele ${ }^{1 *}$ \\ ${ }^{1}$ Laboratory of Microbial Ecology and Technology, Faculty of Bioscience Engineering, Ghent University, Coupure Links 653, \\ B-9000 Ghent, Belgium \\ ${ }^{2}$ Laboratory of Pharmacognosy and Phytochemistry, Faculty of Pharmaceutical Sciences, Ghent University, Harelbekestraat 72, \\ B-9000 Ghent, Belgium \\ ${ }^{3}$ Department of Public Health, Ghent University Hospital, De Pintelaan 185, B-9000 Ghent, Belgium \\ ${ }^{4}$ Biodynamics bvba, E. Vlietinckstraat 20, B-8400 Ostend, Belgium \\ ${ }^{5}$ Department of Gynaecological Oncology, Ghent University Hospital, De Pintelaan 185, B-9000 Ghent, Belgium \\ ${ }^{6}$ Laboratory of Experimental Cancer Research, Department of Experimental Cancer Research, Radiotherapy and Nuclear \\ Medicine, Ghent University Hospital, De Pintelaan 185, B-9000 Ghent, Belgium
}

(Received 6 December 2006 - Revised 23 March 2007 - Accepted 30 March 2007)

Hop-derived food supplements and beers contain the prenylflavonoids xanthohumol (X), isoxanthohumol (IX) and the very potent phyto-oestrogen (plant-derived oestrogen mimic) 8-prenylnaringenin (8-PN). The weakly oestrogenic IX can be bioactivated via $O$-demethylation to 8-PN. Since IX usually predominates over 8-PN, human subjects may be exposed to increased doses of 8-PN. A dietary intervention trial with fifty healthy postmenopausal Caucasian women was undertaken. After a $4 \mathrm{~d}$ washout period, participants delivered faeces, blank urine and breath samples. Next, they started a $5 \mathrm{~d}$ treatment with hop-based supplements that were administered three times per $\mathrm{d}$ and on the last day, a $24 \mathrm{~h}$ urine sample was collected. A semi-quantitative FFQ was used to estimate fat, fibre, alcohol, caffeine and theobromine intakes. The recoveries of IX, 8-PN and $\mathrm{X}$ in the urine were low and considerable inter-individual variations were observed. A five-fold increase in the dosage of IX without change in 8-PN concentration resulted in a significant lower IX recovery and a higher 8-PN recovery. Classification of the subjects into poor (60\%), moderate $(25 \%)$ and strong $(15 \%)$ 8-PN producers based on either urinary excretion or microbial bioactivation capacity gave comparable results. Recent antibiotic therapy seemed to affect the 8-PN production negatively. A positive trend between methane excretion and 8-PN production was observed. Strong 8-PN producers consumed less alcohol and had a higher theobromine intake. From this study we conclude that in vivo $O$-demethylation of IX increases the oestrogenic potency of hop-derived products.

Phyto-oestrogens: Hops: 8-Prenylnaringenin: Post-menopausal women

Phyto-oestrogens are polyphenolic, non-steroidal plant-derived compounds, which are structurally related to $17 \beta$-oestradiol ${ }^{1}$. Predominant phyto-oestrogens in the Western diet belong to the subclasses of isoflavones, lignans and prenylflavonoids ${ }^{2}$. Depending on the endogenous oestrogen levels and the target tissue, these compounds can mimic or modulate the activity of circulating oestrogens resulting in potential health effects ${ }^{3}$. Binding of phyto-oestrogens to the human oestrogen receptors $\alpha$ and $\beta$ is not the only common feature of this quite diverse group. Their bioavailability is characterized by considerable inter-individual variation, which is partly due to differences in metabolism by the gut microbiota ${ }^{4}$ and the background diet ${ }^{5,6}$.
Prenylflavonoids including xanthohumol (X), isoxanthohumol (IX) and 8-prenylnaringenin (8-PN), are found in hops (Humulus lupulus L. Cannabaceae) and hop-derived products such as beers and herbal preparations claiming sedative effects, relief of menopausal complaints or breast enhancement $^{7,8}$. Whereas $X$ and IX have no or weak oestrogenic activity, 8-PN is substantially more oestrogenic than other dietary phyto-oestrogens 9 . 8 -PN is also unique in respect of its oestrogen receptor specificity, as it binds preferably to oestrogen receptor- $\alpha^{10}$.

The weak phyto-oestrogen IX gained much attention recently, since it can be $O$-demethylated into 8 - $\mathrm{PN}$ in vitro 
by the human faecal microbiota ${ }^{11}$ and by mammalian cytochrome $\mathrm{P} 450$ enzymes $^{12,13}$. As its concentration in hop-derived products exceeds that of 8 -PN by over ten-fold ${ }^{14}$, bioactivation of IX might increase the exposure of man to 8-PN. However, analysis of fifty-one faecal samples revealed large inter-individual variation in the IX conversion capacity of the human intestinal bacteria, which led to a separation of individuals in poor, moderate and high 8-PN producers ${ }^{15}$. Until now, this bioactivation has not been studied extensively in vivo. Schaefer et al. ${ }^{16}$ detected 8-PN in the urine of two men after a single dose of $10 \mathrm{mg}$ IX mixed into a high-alcoholic beverage. In a small in vivo trial involving three women, Possemiers et al. ${ }^{15}$ found a clear relationship between the in vitro transformation potential of faecal microbial cultures and the urinary 8-PN excretion after IX consumption.

Understanding the factors influencing the bioactivation of IX in vivo is important to estimate the 8-PN exposure after oral administration of hop-based products. In addition to differences in the composition and activity of the intestinal microbiota, dietary factors may also affect the bioavailability of phyto-oestrogens ${ }^{4}$. Macronutrient intake can selectively modify the growth of gut bacteria involved in the bioactivation of phyto-oestrogens ${ }^{17}$ by changing the intestinal $\mathrm{pH}$, redox potential or transit time or by influencing the availability of substrates ${ }^{18}$. In particular, differences in total fat and dietary fibre consumption have been highlighted in previous studies $5,6,17,19$. The purpose of the present work was: (1) to examine the extent of inter-individual variation in urinary excretion of hop-derived prenylflavonoids; (2) to assess the prevalence of the different 8 -PN producer phenotypes; (3) to evaluate the importance of microbial activation of IX towards 8-PN exposure; (4) to identify microbial and dietary factors that are associated with in vivo 8-PN production. Therefore, a dietary intervention trial with fifty healthy postmenopausal Caucasian women was conducted.

\section{Materials and methods}

\section{Chemicals and reagents}

The isolation of $\mathrm{X}$ from spent hops (i.e. the vegetative residue left after liquid or supercritical $\mathrm{CO}_{2}$ extraction of hop cones; NATECO2, Wolnzach, Germany), isomerization of $\mathrm{X}$ into IX and preparation of 8-PN were performed as described by Possemiers et al. ${ }^{11}$. A stock solution of $15 \mathrm{~mm}$-IX in absolute ethanol was prepared. 4-Hydroxybenzophenone (internal standard) was obtained from Fluka Chemie (Buchs, Switzerland). Type H-1 Helix pomatia extract (min. $300 \mathrm{U} \beta$-glucuronidase/mg and $15 \cdot 3 \mathrm{U}$ sulfatase $/ \mathrm{mg}), \quad p$-nitrophenol, $\quad p$-nitrophenyl$\beta$-D-glucopyranoside and $p$-nitrophenyl- $\beta$-D-glucuronide were obtained from Sigma Aldrich (Bornem, Belgium). All solvents were purchased from Biosolve (Valkenswaard, The Netherlands).

\section{Study design and population}

An intervention trial with fifty healthy post-menopausal Caucasian women was undertaken to study the microbial metabolism of phyto-oestrogens from hops in vivo and in vitro. Women were eligible for participation if they were not using any exogenous hormone medications, not suffering from a gastrointestinal disease and free of cancers. Women who were receiving an antibiotic therapy $(n 2)$ were scheduled at least 1 month after antibiotic therapy completion. Subject information such as date of birth, weight, height, use of pre-, pro-, syn- or antibiotics, smoking and time of last vaginal bleeding were collected upon recruitment.

Participants consumed their habitual Western-type diets, but were asked to abstain from products based on hops during the trial. A list of prenylflavonoid-containing foods was distributed in order to help the volunteers. After a $4 \mathrm{~d}$ washout period, subjects delivered a faecal sample for incubation purposes and microbiological phenotyping, a blank urine sample and two end-expiratory breath samples. Subsequently, three hop-derived dietary supplements per $\mathrm{d}$ were administered during five consecutive days and on the fifth treatment day a $24 \mathrm{~h}$ urine sample was collected. A self-administered semiquantitative FFQ was developed to estimate the usual fat, fibre, alcohol, caffeine and theobromine consumption. This FFQ included questions on the average consumption (frequency, daily portion size) of seventy-six food items during the past year and some additional questions involving more detailed information about some product groups. The inclusion of food items was based on knowledge from previously conducted population dietary surveys in Belgium. The validity and reproducibility of this instrument are reported elsewhere (Bolca et al., unpublished data).

The present study was given ethical approval by the Ethics Committee of the Ghent University Hospital (EC UZG 2005/ 022). The volunteers were fully informed on the aims of the study and gave their written consent.

\section{Sample collection and processing}

End-expiratory breath samples were collected using the QuinTron GaSampler system (Ecce Medical, Schoten, Belgium). The alveolar air samples were analysed immediately by GC-Flame ionisation detector (FID). The background room air was found to contain less than 2 ppm methane. Participants were considered to be methane producers when their breath methane concentration exceeded $3 \mathrm{ppm}^{20}$.

Volumes of the $24 \mathrm{~h}$ urine samples were measured and aliquots were stored at $-20^{\circ} \mathrm{C}$. For hydrolysis of conjugated prenylflavonoids, a $33 \mathrm{~g} / \mathrm{l}$ solution of Type H-1 Helix pomatia extract in sodium acetate buffer $(0 \cdot 1 \mathrm{M}, \mathrm{pH} 5)$ was prepared. Unfrozen urine $(15 \mathrm{ml})$ was added to sodium acetate buffer $(15 \mathrm{ml})$ and $\beta$-glucuronidase/arylsulfatase solution $(30 \mu \mathrm{l})$ and the samples were mixed and incubated for $1 \mathrm{~h}$ at $37^{\circ} \mathrm{C}$. The hydrolysed samples were spiked with $90 \mu$ l internal standard (0.4 M-4-hydroxybenzophenone in ethyl acetate) before extraction. The solid-phase extraction Bond Elut ${ }^{\circledR}$ C18 silica columns ( $5 \mathrm{ml}, 500 \mathrm{mg}$, Varian, St.-Katelijne-Waver, Belgium) were pre-conditioned with $5 \mathrm{ml}$ methanol, $5 \mathrm{ml}$ water and $5 \mathrm{ml}$ sodium acetate buffer $(0 \cdot 1 \mathrm{M}, \mathrm{pH} 5)$, consecutively. After sample application, the cartridges were rinsed with $5 \mathrm{ml}$ water and $5 \mathrm{ml} \mathrm{methanol/water}(2: 3)$ and the compounds of interest were eluted with $2 \mathrm{ml}$ methanol using a VacMaster 20 sample processing unit (IST, Hengoed, Mid Glamorgan, UK). Finally, the solvent was evaporated at room temperature under a gentle stream of $\mathrm{N}_{2}$ and the residue was dissolved in $100 \mu \mathrm{l}$ methanol, transferred into HPLC vials and stored at $-20^{\circ} \mathrm{C}$ prior to analysis. 
Faecal suspensions were prepared by homogenizing $20 \mathrm{~g}$ faeces with $100 \mathrm{ml}$ phosphate buffer $(0.5 \mathrm{M}, \mathrm{pH} 7)$ supplemented with $1 \mathrm{~g} / \mathrm{l}$ sodium thioglycolate. Particulate material was removed by centrifugation at $400 \mathrm{~g}$ for $2 \mathrm{~min}$. To assess the 8-PN production capacity of each faecal culture, in vitro experiments were set up following the incubation and extraction protocols developed by Possemiers et al. ${ }^{11}$. Aliquots of faecal suspensions were also stored at $-80^{\circ} \mathrm{C}$ for measurement of bacterial $\beta$-glucosidase and $\beta$-glucuronidase activities.

\section{Hop-derived dietary supplements}

Two different batches of hop-based capsules (MenoHop ${ }^{\circledR}$, Biodynamics bvba, Ostend, Belgium), were used: twelve women $(24 \%)$ were given BD01 capsules; thirty-eight women $(76 \%)$ ingested BD02 capsules. Composition and manufacturing information have been described by Heyerick et $a l .{ }^{8}$. The concentrations of prenylflavonoids were measured by HPLC-UV after extracting $200 \mathrm{mg}$ of the capsules with $10 \mathrm{ml}$ methanol and diluting the supernatant five times in methanol. BD01 contained $0.23 \pm 0.01 \mathrm{mg}$ IX, $0 \cdot 10 \pm 0.01 \mathrm{mg} 8-\mathrm{PN}$ and $1.38 \pm 0.03 \mathrm{mg} \mathrm{X}$ per capsule; BD02 contained $1.20 \pm 0.04 \mathrm{mg}$ IX, $0.10 \pm 0.01 \mathrm{mg} 8-\mathrm{PN}$ and $2.04 \pm 0.06 \mathrm{mg} X$ per capsule.

\section{Quantification of methane by GC-FID}

Alveolar air samples were taken using a Pressure-Lok precision analytical syringe (Alltech Ass., Deerfield, IL, USA). The methane concentrations were measured with a Chrompack CP 9000 GC equipped with a flame ionization detector (Chrompack, Middelburg, The Netherlands), based on the protocol of Boeckx et al. ${ }^{21}$. The analyses were carried out using the following conditions: injection temperature $65^{\circ} \mathrm{C}$; oven temperature $35^{\circ} \mathrm{C}$; detector temperature $250^{\circ} \mathrm{C}$. A mixture of 50.3 (SD 1.5) ppm $\mathrm{CH}_{4}$ in $\mathrm{Ar}$ was used as standard gas (L'Air Liquide, Liege, Belgium).

\section{Quantification of prenylflavonoids by HPLC-UV}

Quantitative analyses of the prenylflavonoids extracted from the urine samples, incubation media or capsules were performed by HPLC-UV using a Waters 2695 Alliance separations module (Waters, Milford, MA, USA) equipped with a Waters 996 photodiode array detector and Waters Millenium software v3.20 as reported by Possemiers et al. ${ }^{11}$. Detection was done simultaneously at $295 \mathrm{~nm}$ (for IX, 8-PN and 4-hydroxybenzophenone) and at $370 \mathrm{~nm}$ (for X). Peaks were identified by comparison of the retention times and UV spectra with those of authentic isolated reference compounds. Concentrations were calculated based on peak area integration of the analytes and the internal standard.

\section{Measurement of faecal enzyme activity}

Unfrozen faecal suspensions were centrifuged at $5000 \mathrm{~g}$ for $5 \mathrm{~min}$ and diluted five times in phosphate buffer $(0.5 \mathrm{M}, \mathrm{pH} 7)^{22}$. For the assessment of $\beta$-glucosidase and $\beta$-glucuronidase activities, the suspensions were incubated aerobically for $30 \mathrm{~min}$ at $37^{\circ} \mathrm{C}$ with $p$-nitrophenyl- $\beta$-D-glucopyranoside ( $2.5 \mathrm{~mm})$ or $p$-nitrophenyl- $\beta$-D-glucuronide $(2.5 \mathrm{~mm})$, respectively.
Release of $p$-nitrophenol was recorded with a Tecan Sunrise ${ }^{\text {TM }}$ absorbance reader (Tecan Benelux, Mechelen, Belgium) at $405 \mathrm{~nm}$ before and after incubation. The absorbance of a series of different concentrations of $p$-nitrophenol was used to calculate the enzymatic activities, according to the method of Berg et al. ${ }^{23}$.

\section{Statistical approach}

All extractions and analyses were performed in triplicate means and SD were calculated. The Statistical Package for the Social Sciences for Windows version 12.0 (SPSS Inc., Chicago, IL, USA) was used to carry out all statistical analyses. Unless reported differently, a $P$ value of 0.05 was used as threshold for significance. Two-sided significance levels are quoted. Tests for normality of the data and equality of the variances were performed using the Kolmogorov-Smirnov and Levene's test, respectively. Comparison of normally distributed data was performed with Student's $t$ test or ANOVA. The non-parametric Mann-Whitney $U$ and Kruskal-Wallis test were used to compare means of non-normally distributed data. Partial Pearson correlation coefficients adjusted for the type of hop treatment were computed to measure associations between urinary parameters.

Subjects were separated into statistically different groups using the TwoStep cluster analysis protocol. Associations between the producer phenotype and subject characteristics, urinary, microbial and dietary parameters were evaluated using nominal logistic regression with poor 8-PN producers as reference category. Cross-classification analysis calculated the agreement between the in vivo and in vitro data.

\section{Results}

\section{Subject characteristics and diet}

The mean age of the subjects was 57 years with a range from 46 to 74 years. Twenty women $(40 \%)$ were classified as overweight $\left(\mathrm{BMI} \geq 25 \mathrm{~kg} / \mathrm{m}^{2}\right)$; five $(25 \%)$ of these were obese (BMI $\left.\geq 30 \mathrm{~kg} / \mathrm{m}^{2}\right)$. Four women $(8 \%)$ were smokers. The majority had not used antibiotics during the past year and consumed less than one pre-, pro- or synbiotic preparation per month (Table 1). Forty-nine good-quality FFQ (98\%) were included in the analysis. The average consumption of total fat, SFA, MUFA, PUFA, fibre and alcohol was compared with the guideline daily amounts for seniors proposed by the Belgian Health Council ${ }^{24}$ (Table 2). Only $10 \%$ of the study population reported a daily fibre intake of at least $30 \mathrm{~g} / \mathrm{d}$, as recommended. While the Belgian Health Council advises not to drink any alcohol on a regular basis, the Eurodiet

Table 1. Time since last antibiotic therapy and frequency of consumption of pre-, pro- or synbiotic preparations, expressed as a percentage of individuals $(n 50)^{\star}$

\begin{tabular}{lrlr}
\hline Antibiotics (\%) & \multicolumn{2}{c}{ Pre-, pro- or synbiotics (\%) } \\
\hline$\leq 1$ month & 0 & 2 once per week & 14 \\
$1-3$ months & 4 & once per week & 2 \\
$3-6$ months & 8 & 2-3 times per month & 2 \\
$9-12$ months & 10 & once per month & 16 \\
$\geq 1$ year & 78 & never or less than once per month & 66 \\
\hline
\end{tabular}

${ }^{*}$ For details of subjects and procedures, see Materials and methods. 
Table 2. Actual and guideline daily intakes and percentage of the FFQ reports ${ }^{*} \dagger$

(Mean values and standard deviations for forty-nine subjects)

\begin{tabular}{lrrrr}
\hline & \multicolumn{3}{c}{ Consumption $(\mathrm{g} / \mathrm{d})$} & \\
\cline { 2 - 3 } & \multicolumn{2}{c}{ Actual } & & \\
\cline { 2 - 3 } Food item & \multicolumn{1}{c}{ Mean } & \multicolumn{1}{c}{ SD } & Guideline & Subjects (\%) \\
\hline Total fat & 54.18 & 20.83 & $<67$ & 72 \\
SFA & 23.15 & 9.46 & $<22$ & 47 \\
MUFA & 27.00 & 10.40 & $>22$ & 27 \\
PUFA & 9.11 & 3.91 & $12-22$ & 25 \\
Fibre & 19.61 & 6.77 & $>30$ & 10 \\
Alcohol & 8.46 & 12.11 & 0 & 27 \\
Caffeine & 0.15 & 0.10 & US & US \\
Theobromine & 0.03 & 0.04 & US & US \\
\hline
\end{tabular}

* FFQ reports are in agreement with the recommendations for seniors proposed by the Belgian Health Council ${ }^{24}$.

†For details of subjects and procedures, see Materials and methods. US, unspecified.

guideline allows up to $12 \mathrm{~g} / \mathrm{d}^{24}$. The estimated alcohol intake of thirty-seven participants $(76 \%)$ was less than $12 \mathrm{~g} / \mathrm{d}$; thirteen $(35 \%)$ of these reported to drink less than one alcoholic beverage per month. Twenty-eight subjects $(57 \%)$ consumed at least two cups of regular coffee per d (223.82 (SD 61.13) $\mathrm{mg}$ caffeine/d), while twenty-one (43\%) consumed not more than one cup $(125 \mathrm{ml})$ of regular coffee per $\mathrm{d}$ or drank coffee with reduced caffeine content, decaffeinated or surrogate coffee (45.52 (SD 40·00) mg caffeine/d).

\section{Pulmonary methane excretion}

Thirty-three $(66 \%)$ volunteers had methane (4.05-27.95 ppm) in their alveolar air samples and were included in the group of methane producers. The other participants $(34 \%)$ did not exceed the selected methane threshold in their breath $(1.20-$ $3.00 \mathrm{ppm})$. Age, BMI, use of pre-, pro-, syn- or antibiotics, smoking and dietary parameters (total fat, SFA, MUFA, PUFA, fibre, alcohol, caffeine and theobromine intake) were comparable for both methane producers and non-producers.

\section{Urinary excretion and recovery of prenylfavonoids}

IX, 8-PN and $\mathrm{X}$ in the $24 \mathrm{~h}$ urine samples were quantified as daily excretion and percentage of the daily doses recovered (Table 3). The inter-individual variations in urinary excretion were eighteen-fold for IX, thirteen-fold for 8-PN and six-fold for $\mathrm{X}$ between subjects of the BD01 group; between the subjects of the BD02 group, the inter-individual variations were thirty-fold for IX, forty-fold for 8-PN and twenty-seven-fold for X. A thirteen-fold variation in the renal excretion of total prenylflavonoids was observed in both treatment groups. The recoveries of IX, 8-PN and $\mathrm{X}$ were low, especially for $\mathrm{X}$. Less than $1 \%$ of the dosed $\mathrm{X}$ was found in the urine. A 1.5-fold increase in $\mathrm{X}$ dosage resulted in an equivalent rise in urinary $\mathrm{X}$ excretion. In contrast, multiplying the ingested amount of IX with a factor five decreased the recovery of IX significantly $(P=0 \cdot 005)$. Although the capsules contained the same amount of 8 -PN, the average 8 -PN excretion was higher in the BD02 group, but the difference was statistically not significant. When controlling for the type of hop treatment, the urinary recovery of IX correlated modestly with the recovery of 8 -PN $(R 0.293 ; P=0.041)$. There was a stronger correlation between the recoveries of $\mathrm{X}$ and IX $(R \quad 0.445 ; P=0.001)$ and of $\mathrm{X}$ and 8 -PN $(R \quad 0.605$; $P<0.001)$, respectively. Neither the faecal $\beta$-glucosidase (24.6 $\pm 19.9 \mu \mathrm{mol} p$-nitrophenol/h per $\mathrm{g}$ faeces) nor the $\beta$-glucuronidase (15.5 (SD 9.9) $\mu \mathrm{mol} p$-nitrophenol/h per $\mathrm{g}$ faeces) activity correlated with the excretion of IX, 8-PN or X.

Based on the ratio 8-PN:(8-PN + IX) excreted in the urine and the type of hop treatment, three different groups were formed (Fig. 1(A)). Thirty-one (62\%), twelve (24\%) and seven $(14 \%)$ women were classified as poor, moderate and strong in vivo 8-PN producers, respectively. The average urinary recovery of 8 -PN $(P=0 \cdot 014)$ and IX $(P=0.002)$ were significantly different between these groups, while the average recovery of $\mathrm{X}(P=0.374)$ was similar.

\section{Microbial metabolism of prenylflavonoids}

The microbial metabolism of IX was highly variable ranging from 0 up to $100 \%$ IX transformed into 8-PN and led to a separation of the subjects in poor $(61 \%)$, moderate $(27 \%)$ and strong (12\%) in vitro 8-PN producers (Fig. 1(B)). These clusters had significantly different average urinary recoveries of 8 -PN $(P=0.027)$ and $\mathrm{X}(P=0.032)$, but not for IX. The percentages IX transformed and 8 -PN produced by the faecal cultures correlated inversely $(R-0.650, P<0 \cdot 001)$. The prevalence of poor, moderate and strong in vitro $8-\mathrm{PN}$ producers was not significantly influenced by the type of hop treatment.

Table 3. Concentrations of isoxanthohumol (IX), 8-prenylnaringenin (8-PN) and xanthohumol (X) in $24 \mathrm{~h}$ urine samples of post-menopausal women who ingested a hop-based food supplement BD01 $(n 12)$ or BD02 $(n 38)$ three times per $\mathrm{d}$ for $5 \mathrm{~d}^{*}$

(Mean values and standard deviations)

\begin{tabular}{|c|c|c|c|c|c|c|c|c|c|c|c|c|}
\hline \multirow[b]{3}{*}{ Food supplement } & \multicolumn{6}{|c|}{ Excretion $(\mu \mathrm{g} / \mathrm{d})$} & \multicolumn{6}{|c|}{ Recovery (\%) } \\
\hline & \multicolumn{2}{|c|}{$I X^{a}$} & \multicolumn{2}{|c|}{ 8-PN } & \multicolumn{2}{|c|}{$\mathrm{X}$} & \multicolumn{2}{|c|}{$I X^{b}$} & \multicolumn{2}{|c|}{ 8-PN } & \multicolumn{2}{|c|}{$\mathrm{x}$} \\
\hline & Mean & SD & Mean & SD & Mean & SD & Mean & SD & Mean & SD & Mean & SD \\
\hline BD01 & $187 \cdot 3$ & $162 \cdot 1$ & 35.5 & $23 \cdot 6$ & $14 \cdot 2$ & $9 \cdot 2$ & $26 \cdot 9$ & $24 \cdot 6$ & $11 \cdot 6$ & $7 \cdot 8$ & 0.33 & 0.22 \\
\hline BD02 & 287.8 & $200 \cdot 7$ & $51 \cdot 8$ & 38.5 & $19 \cdot 3$ & $10 \cdot 9$ & $8 \cdot 0$ & $5 \cdot 6$ & $16 \cdot 3$ & $12 \cdot 2$ & 0.32 & 0.18 \\
\hline
\end{tabular}

${ }^{\mathrm{a}} P=0.054, \mathrm{BD} 01 v$. BD02.

${ }^{\mathrm{b}} P=0.005, \mathrm{BD} 01$ v. BD02.

${ }^{*}$ For details of subjects and procedures, see Materials and methods. 

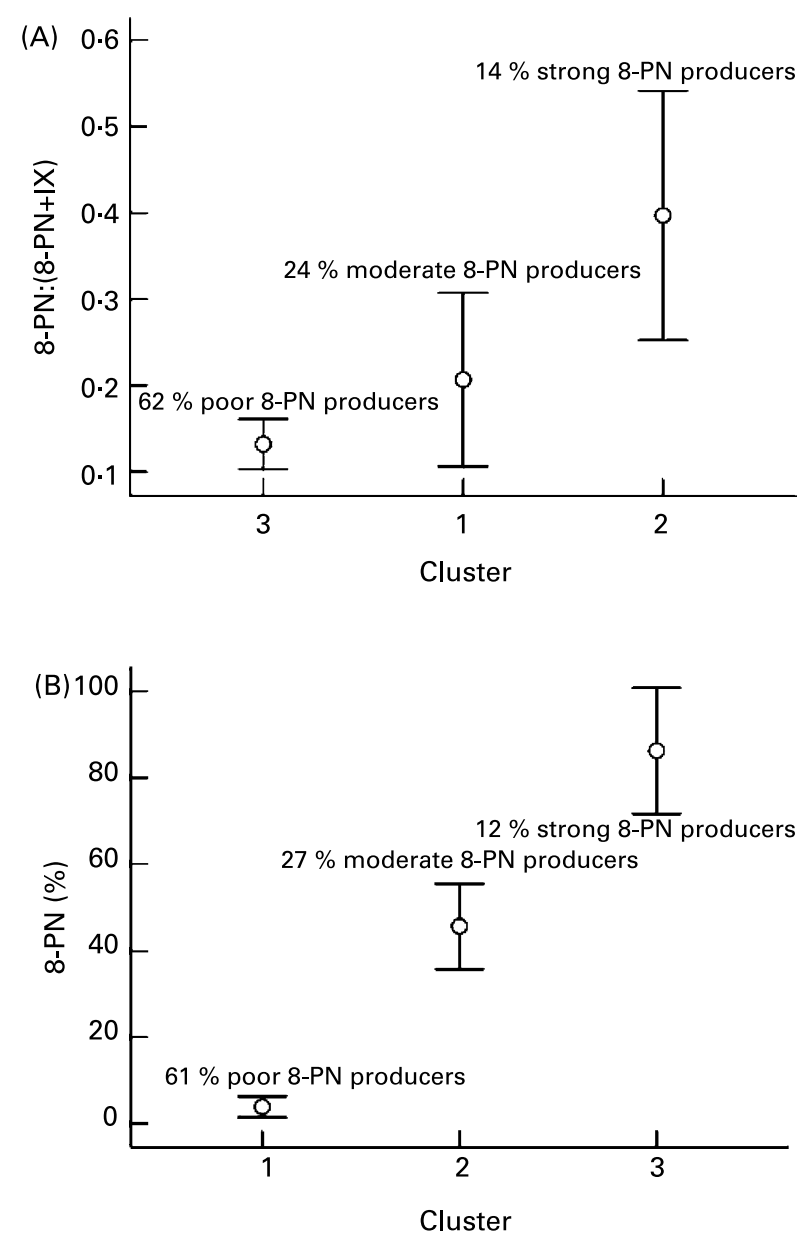

Fig. 1. Clustering of individuals ( $n 50)$ in three significantly different groups, namely, poor, moderate and strong 8-prenylnaringenin (8-PN) producers, based on (A) the ratio 8-PN:(8-PN + isoxanthohumol (IX)) excreted in the $24 \mathrm{~h}$ urine and the type of hop treatment; (B) the capacity of the faecal microbiota to convert IX in 8-PN. Values are means with their standard deviations represented by vertical bars. For details of subjects and procedures, see Materials and methods.

\section{Factors associated with 8-prenylnaringenin production}

Associations between the in vivo 8-PN producer phenotype and subject characteristics, microbial and dietary parameters are presented in Table 4. Individuals who had not taken antibiotics at least 6 months before participation were more likely to be strong in vivo 8 -PN producers $(P=0.035)$. There was some indication $(0.050<P<0.075)$ that pulmonary methane excretion was positively related with in vivo 8-PN production. A lower reported alcohol consumption $(P=0.039)$ and a higher intake of theobromine $(P=0.050)$ were associated with the strong in vivo 8-PN producer phenotype.

Most of the subject characteristics, urinary, microbial and dietary parameters were not strongly associated with the in vitro 8-PN producer phenotype (Table 5). However, positive trends $(0.050<P<0.075)$ between urinary excretion and recovery of $\mathrm{X}$ and in vitro 8-PN production were observed. Lower estimated alcohol $(P=0 \cdot 041)$ and higher theobromine intake $(P=0 \cdot 047)$ correlated with the in vitro strong $8-\mathrm{PN}$ producer phenotype.

As alcohol consumption differed between the 8-PN producer phenotypes, this topic was examined more thoroughly.
Alcoholic beverages were included in four items of the FFQ: aperitif; wine and champagne; beer; liqueurs and spirits. In addition to the frequency and daily portion size of beer consumption, questions on the type of beer (no or low alcoholic, pilsner type or strong beer) were included to estimate the usual intake of both alcohol and prenylflavonoids. Neither in vivo nor in vitro 8-PN production correlated significantly with the usual beer consumption. Twenty-six women $(53 \%)$ reported to drink less than $200 \mathrm{ml}$ beer per month, whereas the others had an average estimated beer consumption of 56 (SD 70 ) $\mathrm{ml} / \mathrm{d}$. Habitual X, IX, 8-PN and total prenylflavonoid intakes were similar in all 8-PN producer phenotypes and ranged from 0 to $102 \mu \mathrm{g} / \mathrm{d}$ for $\mathrm{X}, 0$ to $630 \mu \mathrm{g} / \mathrm{d}$ for IX, 0 to $21 \mu \mathrm{g} / \mathrm{d}$ for 8-PN and 0 to $753 \mu \mathrm{g} / \mathrm{d}$ for total prenylflavonoids.

Cross-classification analyses for 8-PN producer phenotypes estimated from in vivo and in vitro data indicated that six women $(12.2 \%)$ were misclassified, while twenty-six subjects $(53.1 \%)$ were classified correctly and forty-three participants $(87.7 \%)$ were classified correctly or in the adjacent category.

\section{Discussion}

The prenylflavonoids $\mathrm{X}$, IX and 8-PN are found in hops (Humulus lupulus L. Cannabaceae) and hop-derived products, including beers and food supplements. As bioactivation of IX to the potent phyto-oestrogen 8-PN might increase the oestrogenic potency of such products, the metabolism of prenylflavonoids was studied in vivo and in vitro. In order to work with the target population for phyto-oestrogen therapy and to minimize the variations in circulating oestrogen concentrations and their possible interactions with the phyto-oestrogen metabolism $^{25}$ and liver enzymes ${ }^{26}$, only healthy hormonenaive women were included. The recoveries of the dosed IX, 8-PN and $\mathrm{X}$ were low and considerable inter-individual variations were observed. Classification of the volunteers into poor $(60 \%)$, moderate $(25 \%)$ and strong $(15 \%) 8$-PN producers based on either urinary excretion or microbial bioactivation capacity of faecal samples gave comparable results. Recent antibiotic therapy seemed to affect the 8-PN production negatively. A positive trend between methane excretion and 8-PN production was observed. A lower alcohol and a higher theobromine intake were associated with the strong 8-PN producer phenotype.

Less than $1 \%$ of the administered $\mathrm{X}$ was excreted in the urine and a 1.5-fold increase in $\mathrm{X}$ dosage resulted in an equivalent rise in urinary excretion. After oral administration of 20 to $500 \mathrm{mg} / \mathrm{kg}$ body weight $\mathrm{X}$ as a pure compound or as a hop extract, Avula et al. ${ }^{27}$ found $0.06-0.49 \%$ of the dosed X in the urine and more than $99.5 \%$ in the faeces of rats. These results suggest that $\mathrm{X}$ is poorly absorbed through the intestinal wall, thereby resulting in a low oral bioavailability. This feature may be an important bottleneck in the development of $\mathrm{X}$ as a novel broad-spectrum cancer chemopreventive agent ${ }^{28}$. Based on the apparent permeability coefficients assessed in the Caco-2 cell monolayer model, Nikolic et al. ${ }^{29}$ predicted a rather efficient intestinal absorption via passive diffusion for 8-PN. This rapid enteral absorption was also found after a single oral administration of 8-PN to healthy postmenopausal women ${ }^{30}$, as well as in the present study. The recoveries of 8 -PN and IX in the $24 \mathrm{~h}$ urine samples 
Table 4. Subject characteristics, microbial and dietary parameters in relation to the in vivo 8-prenylnaringenin (8-PN) producer phenotype, expressed as OR and upper and lower $95 \% \mathrm{Cl}$ derived from nominal logistic regression with poor in vivo 8-PN producers as reference category*

\begin{tabular}{|c|c|c|c|c|c|c|}
\hline & \multicolumn{6}{|c|}{ In vivo 8-PN producer } \\
\hline & \multicolumn{3}{|c|}{ Moderate } & \multicolumn{3}{|c|}{ Strong } \\
\hline & \multirow[b]{2}{*}{ OR } & \multicolumn{2}{|c|}{$95 \% \mathrm{Cl}$} & \multirow[b]{2}{*}{ OR } & \multicolumn{2}{|c|}{$95 \% \mathrm{Cl}$} \\
\hline & & Upper & Lower & & Upper & Lower \\
\hline \multicolumn{7}{|l|}{ Subject characteristics } \\
\hline Age (years) & 0.986 & $0 \cdot 870$ & 1.118 & 0.945 & 0.792 & $1 \cdot 128$ \\
\hline BMI $\left(\mathrm{kg} / \mathrm{m}^{2}\right)$ & 1.097 & 0.919 & $1 \cdot 310$ & 0.999 & 0.780 & 1.278 \\
\hline \multicolumn{7}{|l|}{ Smoking } \\
\hline Yes & 0.000 & 0.000 & 0.000 & 0.000 & 0.000 & 0.000 \\
\hline \multirow{2}{*}{\multicolumn{7}{|c|}{ Use of antibiotics }} \\
\hline & & & & & & \\
\hline $1-3$ months & $2 \cdot 500$ & 0.142 & 43.97 & 0.000 & 0.000 & 0.000 \\
\hline $3-6$ months & 0.833 & 0.077 & 8.995 & 0.000 & 0.000 & 0.000 \\
\hline $6-12$ months & 0.000 & 0.000 & 0.000 & $9 \cdot 375$ & $1 \cdot 174$ & $74 \cdot 84$ \\
\hline$\geq 1$ year & 1.000 & \multicolumn{2}{|c|}{ Reference } & 1.000 & \multicolumn{2}{|c|}{ Reference } \\
\hline \multicolumn{7}{|l|}{ Microbial parameters } \\
\hline \multicolumn{6}{|l|}{ Enzyme activities ( $\mu \mathrm{mol} / \mathrm{h}$ per $\mathrm{g})$} & 3.858 \\
\hline$\beta$-glucuronidase & 1.056 & 0.970 & $1 \cdot 151$ & 0.935 & 0.825 & 1.061 \\
\hline$\beta$-glucosidase & 1.039 & 0.987 & 1.094 & 1.065 & 1.002 & $1 \cdot 132$ \\
\hline \multicolumn{7}{|l|}{ Faecal metabolism } \\
\hline Degradation of IX & 1.033 & 0.990 & 1.079 & 0.989 & 0.946 & 1.034 \\
\hline Production of 8-PN & 1.041 & 0.988 & 1.096 & 1.011 & 0.957 & 1.067 \\
\hline \multicolumn{7}{|l|}{ Dietary parameters } \\
\hline \multicolumn{7}{|l|}{ Fat consumption (g/d) } \\
\hline Total fat & 1.538 & 0.565 & $4 \cdot 189$ & $0 \cdot 700$ & 0.192 & $2 \cdot 558$ \\
\hline SFA & 0.523 & 0.169 & 1.618 & 1.670 & 0.383 & $7 \cdot 291$ \\
\hline Unsaturated fatty acids & 0.638 & 0.246 & 1.658 & $1 \cdot 327$ & 0.386 & 4.564 \\
\hline MUFA & 1.326 & 0.556 & $3 \cdot 165$ & 0.934 & 0.383 & $2 \cdot 277$ \\
\hline PUFA & 1.042 & 0.878 & $1 \cdot 236$ & 0.926 & 0.726 & $1 \cdot 180$ \\
\hline \multicolumn{7}{|l|}{ Fat consumption (\%) } \\
\hline SFA & 0.822 & 0.492 & 1.374 & $1 \cdot 115$ & 0.620 & $2 \cdot 007$ \\
\hline Unsaturated fatty acids & 0.939 & 0.634 & 1.392 & 0.992 & 0.607 & 1.622 \\
\hline Fibre consumption (g/d) & $1 \cdot 103$ & 0.991 & 1.227 & 1.051 & 0.927 & $1 \cdot 191$ \\
\hline Fat:fibre ratio & 0.617 & 0.317 & $1 \cdot 202$ & 0.665 & 0.312 & 1.416 \\
\hline Alcohol consumption (g/d) & 0.799 & 0.350 & 1.821 & 0.257 & 0.071 & 0.933 \\
\hline \multicolumn{7}{|l|}{ Methylxanthine intake (mg/d) } \\
\hline Caffeine & 1.000 & 0.991 & 1.009 & 0.998 & 0.987 & 1.010 \\
\hline Theobromine & $0 \cdot 757$ & 0.395 & 1.451 & $2 \cdot 041$ & 0.793 & $5 \cdot 255$ \\
\hline \multicolumn{7}{|l|}{ Pre-, pro-, synbiotics } \\
\hline$\geq$ once per week & 1.500 & 0.224 & $10 \cdot 04$ & $1 \cdot 313$ & 0.115 & $15 \cdot 03$ \\
\hline once per week & $6.6 \mathrm{E} 8$ & $6.6 \mathrm{E} 8$ & $6.6 \mathrm{E} 8$ & 1.016 & 1.016 & 1.016 \\
\hline $2-3$ times per month & 0.000 & 0.000 & 0.000 & 0.000 & 0.000 & 0.000 \\
\hline once per month & $1 \cdot 200$ & 0.189 & $7 \cdot 628$ & 1.050 & 0.095 & 11.56 \\
\hline$\leq$ once per month & 1.000 & \multicolumn{2}{|c|}{ Reference } & 1.000 & \multicolumn{2}{|c|}{ Reference } \\
\hline
\end{tabular}

${ }^{*}$ For details of subjects and procedures, see Materials and methods.

IX, isoxanthohumol.

were comparable to those reported for the isoflavones genistein $(8-16 \%)$ and daidzein $(15-50 \%)^{31-33}$.

The observed inter-individual variation in urinary excretion of prenylflavonoids was considerable and higher than the $5 \cdot 5$-fold variation in $24 \mathrm{~h}$ renal excretion of 8 -PN reported by Schaefer et al. ${ }^{16}$ in a small trial involving six subjects. In comparison, concentrations of the isoflavones genistein and daidzein in $24 \mathrm{~h}$ urine samples varied between subjects twelve- to twenty-four-fold and thirteen to eightyfive-fold, respectively ${ }^{5,32,34}$. Lampe et $a .^{35}$ and Rowland et al. ${ }^{17}$ reported a wider range of excretion of the microbial daidzein metabolites equol and $O$-desmethylangolensin and the enterolignans enterolacton and enterodiol in human subjects.
The urinary recovery data indicated that the excretion of IX and 8-PN was dependent on the ingested amount of IX. A five-fold increase in IX dosage decreased the recovery of IX significantly. Simultaneously, the average 8-PN excretion increased although the ingested amount of 8-PN was unchanged. This is probably due to the conversion of IX into 8-PN in vivo. Urinary excretion of 8-PN after consumption of IX has also been reported by Schaefer et al. ${ }^{16}$ and Possemiers et al. ${ }^{15}$, and in both studies inter-individual differences were noticed. In addition, the urinary recovery of 8-PN was significantly different between poor, moderate and strong 8-PN producers. As the prevalence of the different 8-PN producer phenotypes was equivalent in both treatment groups, these results suggest that the extent of the conversion 
Table 5. Subject characteristics, urinary, microbial and dietary parameters in relation to the in vitro 8-prenylnaringenin (8-PN) producer phenotype, expressed as OR and upper and lower $95 \% \mathrm{Cl}$ derived from nominal logistic regression with poor in vitro 8-PN producers as reference category*

\begin{tabular}{|c|c|c|c|c|c|c|}
\hline & \multicolumn{6}{|c|}{ In vitro 8-PN producer } \\
\hline & \multicolumn{3}{|c|}{ Moderate } & \multicolumn{3}{|c|}{ Strong } \\
\hline & \multirow[b]{2}{*}{ OR } & \multicolumn{2}{|c|}{$95 \% \mathrm{Cl}$} & \multirow[b]{2}{*}{ OR } & \multicolumn{2}{|c|}{$95 \% \mathrm{Cl}$} \\
\hline & & Upper & Lower & & Upper & Lower \\
\hline \multicolumn{7}{|l|}{ Subject characteristics } \\
\hline Age (years) & $1 \cdot 117$ & 0.986 & 1.265 & $1 \cdot 104$ & 0.938 & 1.300 \\
\hline $\mathrm{BMI}\left(\mathrm{kg} / \mathrm{m}^{2}\right)$ & 1.043 & 0.880 & 1.236 & 0.992 & 0.789 & 1.247 \\
\hline \multicolumn{7}{|l|}{ Smoking } \\
\hline Yes & $2 \cdot 265$ & 0.100 & 51.41 & 0.000 & 0.000 & 0.000 \\
\hline No & 1.000 & \multicolumn{2}{|c|}{ Reference } & 1.000 & \multicolumn{2}{|c|}{ Reference } \\
\hline \multicolumn{7}{|l|}{ Use of antibiotics } \\
\hline $1-3$ months & $1 \cdot 171$ & 0.041 & 33.52 & 0.000 & 0.000 & 0.000 \\
\hline $3-6$ months & 0.417 & 0.020 & 8.920 & 0.000 & 0.000 & 0.000 \\
\hline $6-12$ months & $2 \cdot 872$ & 0.311 & $26 \cdot 55$ & 2.646 & 0.177 & 39.50 \\
\hline$\geq 1$ year & 1.000 & \multicolumn{2}{|c|}{ Reference } & 1.000 & \multicolumn{2}{|c|}{ Reference } \\
\hline \multicolumn{7}{|l|}{ Urinary parameters } \\
\hline \multicolumn{7}{|l|}{ Urinary excretion $(\mu \mathrm{g} / \mathrm{d})$} \\
\hline IX & 1.000 & 0.996 & 1.004 & 0.993 & 0.982 & 1.004 \\
\hline 8-PN & 0.965 & 0.926 & 1.006 & 0.978 & 0.930 & 1.027 \\
\hline IX & 0.985 & 0.874 & $1 \cdot 109$ & $1 \cdot 165$ & 0.980 & 1.384 \\
\hline \multicolumn{7}{|l|}{ Urinary recovery (\%) } \\
\hline IX & 0.950 & 0.465 & 1.943 & 0.882 & 0.334 & $2 \cdot 330$ \\
\hline 8-PN & 0.900 & 0.789 & 1.027 & 0.943 & 0.820 & 1.086 \\
\hline $\mathrm{x}$ & 0.272 & 0.000 & $199 \cdot 0$ & 689.0 & 0.269 & $1.7 \mathrm{E} 6$ \\
\hline \multicolumn{7}{|l|}{ Microbial parameters } \\
\hline \multicolumn{6}{|l|}{ Enzyme activities ( $\mu \mathrm{mol} / \mathrm{h}$ per $\mathrm{g}$ ) } & 2.502 \\
\hline$\beta$-glucuronidase & 1.015 & 0.948 & 1.087 & 1.023 & 0.931 & 1.123 \\
\hline$\beta$-glucosidase & 0.999 & 0.965 & 1.034 & 0.999 & 0.943 & 1.058 \\
\hline \multicolumn{7}{|l|}{ Dietary parameters } \\
\hline \multicolumn{7}{|l|}{ Fat consumption (g/d) } \\
\hline Total fat & 1.224 & 0.473 & $3 \cdot 163$ & 0.224 & 0.036 & 1.412 \\
\hline SFA & 0.820 & 0.279 & 2.410 & 6.392 & 0.821 & $49 \cdot 76$ \\
\hline Unsaturated fatty acids & 0.604 & 0.200 & 1.821 & 4.485 & 0.847 & 23.74 \\
\hline MUFA & 1.583 & 0.600 & $4 \cdot 180$ & 0.901 & 0.341 & $2 \cdot 381$ \\
\hline PUFA & 0.644 & 0.329 & 1.264 & 1.092 & 0.643 & 1.853 \\
\hline Fat consumption (\%) & & & & & & \\
\hline SFA & 0.956 & 0.593 & 1.539 & 2.088 & 0.919 & 4.746 \\
\hline Unsaturated fatty acids & 0.921 & 0.659 & 1.350 & 1.732 & 0.882 & 3.402 \\
\hline Fibre consumption (g/d) & 1.025 & 0.927 & $1 \cdot 132$ & 1.065 & 0.940 & 1.208 \\
\hline Fat:fibre ratio & 1.045 & 0.656 & 1.665 & 1.170 & 0.674 & 2.033 \\
\hline Alcohol consumption (g/d) & 0.893 & 0.396 & 2.014 & 0.152 & 0.021 & 1.092 \\
\hline Methylxanthine intake (mg/d) & & & & & & \\
\hline Caffeine & 1.002 & 0.995 & 1.009 & 0.991 & 0.980 & 1.003 \\
\hline Theobromine & 0.923 & 0.479 & 1.779 & 1.450 & 0.552 & 3.811 \\
\hline Pre-, pro-, synbiotics & & & & & & \\
\hline$\geq$ once per week & 0.425 & 0.042 & 4.352 & $2 \cdot 125$ & 0.283 & $15 \cdot 97$ \\
\hline once per week & 0.000 & 0.000 & 0.000 & 0.000 & 0.000 & 0.000 \\
\hline $2-3$ times per month & 0.000 & 0.000 & 0.000 & 0.000 & 0.000 & 0.000 \\
\hline once per month & 0.243 & 0.026 & $2 \cdot 272$ & 0.000 & 0.000 & 0.000 \\
\hline$\leq$ once per month & 1.000 & & ence & 1.000 & $\operatorname{Re}$ & ence \\
\hline
\end{tabular}

${ }^{*}$ For details of subjects and procedures, see Materials and methods.

IX, isoxanthohumol; $\mathrm{X}$, xanthohumol.

depends on the IX dose administered. Cross-over studies with different IX doses are warranted to investigate this in more detail.

The 8-PN production was estimated from in vivo as well as in vitro data. The study population was separated into poor $(62 \%)$, moderate $(24 \%)$ and strong $(14 \%)$ in vivo 8-PN producers. Based on the microbial bioactivation capacity of the faecal cultures, a similar classification prevailed. This is in quite good agreement with the incubation experiments of
Possemiers et al. ${ }^{15}$, which separated faecal samples into slow $(63 \%)$, moderate $(21 \%)$ and high $(16 \%)$ IX converters. The hypothesis that microbial and dietary factors give rise to these different 8-PN producer phenotypes was tested.

The inverse relationship between use of antibiotics and 8-PN production indicates that intestinal microbiota are involved. Pulmonary methane excretion may serve as an indicator of methane production by intestinal microbiota ${ }^{36}$. All humans harbour methanogens in the colon, but methane 
only appears in the breath if the concentration of Methanobrevibacter smithii exceeds $10^{8} / \mathrm{g}$ dry weight faeces ${ }^{37}$. Agerelated increases in transit time and carbohydrate malabsorption promote methanogenesis ${ }^{38}$ and may explain the high prevalence of methane producers in the present study. $\mathrm{H}_{2}$ gas is formed in the colon by a variety of hydrolytic and saccharolytic bacteria to dispose reducing equivalents during fermentation ${ }^{39}$ and is consumed by methanogenic, homoacetogenic and sulphate-reducing microbiota. Comparison of the prevalence of the different $\mathrm{H}_{2}$-consuming microbiota in faecal samples of poor, moderate and strong 8-PN producers will unravel the relationship between pulmonary methane excretion and 8-PN production.

Several observational studies have reported differences in dietary intake, particularly fat and fibre, in relation to equol and enterolignan production capacities $5,6,17,19$. The present study did not reveal significant differences. To our knowledge, the effects of alcohol, caffeine, and theobromine consumption on the gut microbiota and, hence, their phyto-oestrogen metabolism have not been investigated directly. As these compounds are rapidly and almost completely absorbed in the stomach and the small intestine, they are not expected to importantly affect the intestinal bacteria, although caffeine intake has been associated with the microbial metabolism of daidzein $^{25,40}$. There is some suggestive evidence for an inhibitory effect of alcohol on the activity of CYP1A2 $2^{41,42}$, the mammalian enzyme system that has been shown to demethylate IX into 8-PN in vitro ${ }^{12}$. Thus, the involvement of hepatic enzymes in the bioactivation of IX as suggested by Schaefer et $a l .{ }^{16}$ may explain why a lower reported alcohol consumption was associated with the likelihood of being a strong in vivo 8-PN producer. CYP1A2 activity accounts for almost $95 \%$ of the demethylation of caffeine ${ }^{43}$, but contributes only partially to the elimination of theobromine ${ }^{44}$. Although low and high caffeine consumers were equally present in the current study population, intake of this CYP1A2 inducer could not be linked to 8-PN production. The mechanism of the positive correlation between theobromine consumption and the strong 8-PN producer phenotype remains unclear. As a constituent of cacao, theobromine is consumed by a large proportion of the population, but it possesses little pharmacological activity. It is important to note that only $10 \%$ of the study population had a daily fibre intake above $30 \mathrm{~g}$, as recommended for seniors by the Belgian Health Council ${ }^{24}$. As a consequence, the effect of fibre consumption or the fat: fibre ratio on the conversion of IX into 8-PN may have been overlooked in this study. Similarly, the influence of the well-known induction of CYP1A2 activity by tobacco smoking could not be clarified, as only four participants $(8 \%)$ were smokers. Even though the present study was not specifically designed to address this question, it is unlikely that prior consumption of hop-derived products influences the ability to convert IX into 8-PN, since no differences in the habitual intake of prenylflavonoids were found between the different 8-PN producer phenotypes. Analogously, soya intervention studies failed to stimulate equol production in low equol producers ${ }^{45,46}$.

Cross-classification analyses for 8-PN producer phenotype estimated from in vivo and in vitro data indicated that $12.2 \%$ of the women were misclassified, while $53.1 \%$ were classified correctly. This shows that the in vitro incubation experiments give a good indication of the 8-PN producer phenotype and, additionally, stresses the important contribution of the intestinal microbiota towards the in vivo bioactivation of IX. Although the in vivo bioavailability is the final result of intestinal absorption, human and microbial metabolism, cellular retention, distribution and excretion, these results show the potential of faecal incubations as an appropriate screening assay.

Although biotransformation is generally regarded as a process of metabolic inactivation prior to excretion, there are many well-known examples of metabolic activation. Demethylation by cytochrome P450 enzymes or by gut microbiota represents a common metabolic pathway for activation of pro-oestrogens, such as the isoflavone formononetin ${ }^{47,48}$ and the synthetic steroid mestranol ${ }^{49}$. Similarly, in vivo $O$-demethylation of IX into 8-PN increased the oestrogenic potency of the hop-derived food supplements in this study, since inter-individual differences in daily excretion of more than $200 \mu \mathrm{g} 8$-PN or $2-20 \mu \mathrm{g} 17 \beta$-oestradiol equivalents ${ }^{50}$ were observed.

In summary, we showed that individuals can be phenotyped as poor $(60 \%)$, moderate $(25 \%)$ or strong $(15 \%)$ 8-PN producers based on either urinary excretion data or faecal incubation experiments. This inter-individual variation in 8-PN production could be linked to differences in microbial and dietary factors. From this study, we conclude that the oestrogenic potency of hop-derived products depends on the 8-PN producer phenotype and the concentration of IX.

\section{Acknowledgements}

This work was funded by a $\mathrm{PhD}$ grant of the Institute for the Promotion of Innovation through Science and Technology in Flanders (IWT-Vlaanderen) to Selin Bolca. Tom Van de Wiele is a postdoctoral fellow of the fund for scientific research - Flanders (Belgium) (FWO-Vlaanderen). We thank Marleen Temmerman and Marleen De Block for help in recruiting participants. We also acknowledge the women who generously volunteered for this trial. Lynn Vanhaecke is gratefully thanked for critically reading the manuscript.

\section{References}

1. Adlercreutz H (2002) Phyto-oestrogens and cancer. Lancet Oncol 3, 364-373.

2. Fletcher RJ (2003) Food sources of phyto-oestrogens and their precursors in Europe. Br J Nutr 89, S39-S43.

3. Ososki AL \& Kennely EJ (2003) Phytoestrogens: a review of the present state of research. Phytother Res 17, 845-869.

4. Rowland IR, Faughnan M, Hoey L, Wähälä K, Williamson G \& Cassidy A (2003) Bioavailability of phyto-estrogens. Br J Nutr 89, S45-S58.

5. Blakesmith SJ, Lyons-Wall PM, Joannou GE, Petocz P \& Samman S (2005) Urinary isoflavonoid excretion is inversely associated with the ratio of protein to dietary fibre intake in young women. Eur J Nutr 59, 284-290.

6. Horner NK, Kristal AR, Prunty J, Skor HE, Potter JD \& Lampe JW (2002) Dietary determinants of plasma enterolactone. Cancer Epidemiol Biomarkers Prev 11, 121-126.

7. Coldham NG \& Sauer MJ (2001) Identification, quantitation and biological activity of phytoestrogens in a dietary supplement for breast enhancement. Food Chem Toxicol 39, 1211-1224. 
8. Heyerick A, Vervarcke S, Depypere HT, Bracke ME \& De Keukeleire D (2006) A first prospective, randomized, doubleblind, placebo-controlled study on the use of a standardized hop extract to alleviate menopausal discomforts. Maturitas 54, $164-175$

9. Milligan SR, Kalita JC, Heyerick A, Rong H, De Cooman L \& De Keukeleire D (1999) Identification of a potent phytoestrogen in hops (Humulus lupulus L.) and beer. J Clin Endocrinol Metab 83, 2249-2252.

10. Schaefer O, Hümpel $M$, Fritzemeier K-H, Bohlmann $\mathrm{R}$ \& Schleuning W-D (2003) 8-prenylnaringenin is a potent ER $\alpha$ selective phytoestrogen present in hops and beer. J Steroid Biochem Mol Biol 84, 359-360.

11. Possemiers S, Heyerick A, Robbens V, De Keukeleire D \& Verstraete W (2005) Activation of pro-estrogens form hops (Humulus lupulus L.) by intestinal microbiota; conversion of isoxanthohumol into 8-prenylnaringenin. J Agric Food Chem 53, 6281-6288.

12. Guo J, Nikolic D, Chadwick LR, Pauli GF \& van Breemen RB (2006) Identification of human hepatic cytochrome P450 enzymes involved in the metabolism of 8-prenylnaringenin and isoxanthohumol form hops (Humulus lupulus L.). Drug Metab Dispos 34, 1152-1159.

13. Nikolic D, Li Y, Chadwick LR, Grubjesic S, Schwab P, Metz P \& van Breemen RB (2004) Metabolism of 8-prenylnaringenin, a potent phytoestrogen from hops (Humulus lupulus), by human liver microsomes. Drug Metab Dispos 32, 272-279.

14. Stevens JF, Taylor AW \& Deinzer ML (1999) Quantitative analysis of xanthohumol and related prenylflavonoids in hops and beer by liquid chromatography-tandem mass spectrometry. J Chromatogr A 832, 97-107.

15. Possemiers S, Bolca S, Grootaert C, Heyerick A, Decroos K, Dhooge W, De Keukeleire D, Rabot S, Verstraete W \& Van de Wiele T (2006) Isoxanthohumol from hops (Humulus lupulus L.) is activated into the potent phytoestrogen 8-prenylnaringenin in vitro and in the human intestine. J Nutr 136, 1862-1867.

16. Schaefer O, Bohlmann R, Schleuning W-D, Schulze-Forster K \& Hümpel M (2005) Development of a radioimmunoassay for the quantitative determination of 8-prenylnaringenin in biological matrices. J Agric Food Chem 53, 2881-2889.

17. Rowland IR, Wiseman H, Sanders TAB, Adlercreutz H \& Bowey EA (2000) Interindividual variation in metabolism of soy isoflavones and lignans: influence of habitual diet on equol production by the gut microflora. Nutr Cancer 36, 27-32.

18. Cummings JH \& Macfarlane GT (1991) The control and consequences of bacterial fermentation in the human colon. $J$ Appl Bacteriol 70, 443-459.

19. Frankenfeld CL, Patterson RE, Horner NK, Neuhouser ML, Skor HE, Kalhorn TF, Howald WN \& Lampe JW (2003) Validation of a soy food frequency questionnaire and evaluation of correlates of plasma isoflavone concentrations in postmenopausal women. Am J Clin Nutr 77, 674-680.

20. Soares ACF, Lederman HM, Fagundes-Neto U \& de Morais MB (2005) Breath methane associated with slow colonic transit time in children with chronic constipation. J Clin Gastroenterol 39, 512-515.

21. Boeckx P, Van Cleemput O \& Villaralvo I (1996) Methane emission from a landfill and the methane oxidising capacity of its covering soil. Soil Biol Biochem 28, 1397-1405.

22. Hoey L, Rowland IR, Lloyd AS, Clarke DB \& Wiseman H (2004) Influence of soya-based infant formula consumption on isoflavone and gut microflora metabolite concentrations in urine and on faecal microflora composition and metabolic activity in infants and children. Br J Nutr 91, 607-616.

23. Berg JO, Nord CE \& Wadstrom T (1978) Formation of glycosidases in batch and continuous cultures of Bacteroides fragilis. Appl Environ Microbiol 35, 269-273.
24. Superior Health Council (2006) Recommended daily allowances in Belgium: revisions November 2006, 1st ed. Brussels: Federal Public Service Health, Food Chain Safety Environment.

25. Frankenfeld CL, McTiernan A, Tworoger SS, et al. (2004) Serum steroid hormones, sex hormone-binding globulin concentrations and urinary hydroxylated estrogen metabolites in post-menopausal women in relation to daidzein-metabolizing phenotypes. J Steroid Biochem Mol Biol. 88, 399-408.

26. Pollock BG, Wylie M \& Stack JA (1999) Inhibition of caffeine metabolism by estrogen replacement therapy in postmenopausal women. J Clin Pharmacol 39, 936-940.

27. Avula B, Ganzera M, Warnick JE, Feltenstein MW, Sufka KJ \& Khan IA (2004) High-performance liquid chromatographic determination of xanthohumol in rat plasma, urine and fecal samples. J Chromatogr Sci 42, 378-382.

28. Gerhaüser C, Alt A, Heiss E, et al. (2002) Cancer chemopreventive activity of xanthohumol, a natural product derived from hop. Mol Cancer Ther. 1, 959-969.

29. Nikolic D, Li Y, Chadwick LR \& van Breemen RB (2006) In vitro studies of intestinal permeability and hepatic and intestinal metabolism of 8-prenylnaringenin, a potent phytoestrogen form hops (Humulus lupulus L.). Pharm Res 23, $864-872$

30. Rad M, Hümpel M, Schoemaker RC, Schleuning W-D, Cohen AF \& Burggraaf J (2006) Pharmacokinetics and systemic endocrine effects of the phyto-oestrogen 8-prenylnaringenin after single oral doses to postmenopausal women. Br J Clin Pharmacol 62, 288-296.

31. Setchell KDR, Brown NM, Desai PB, Zimmer-Nechimias L, Wolfe B, Jakate AS, Creutzinger V \& Heubi JE (2003) Bioavailability, disposition, and dose-response effects of soy isoflavones when consumed by healthy women at physiologically typical dietary intakes. J Nutr 133, 1027-1035.

32. Wiseman H, Casey K, Bowey EA, Duffy R, Davies M, Rowland IR, Lloyd AS, Murray A, Thompson A \& Clarke DB (2004) Influence of $10 \mathrm{wk}$ of soy consumption on plasma concentrations and excretion of isoflavonoids and on gut microflora metabolism in healthy adults. Am J Clin Nutr 80, 692-699.

33. Xu X, Wang H, Murphy PA, Cook L \& Hendrich S (1994) Daidzein is a more bioavailable soymilk isoflavone than is genistein in adult women. $J$ Nutr 124, 825-832.

34. Karr SC, Lampe JW, Huchins AM \& Slavin JL (1997) Urinary isoflavonoid excretion in humans is dose dependent at low to moderate levels of soy-protein consumption. Am J Clin Nutr 66, 46-51.

35. Lampe JW, Karr SC, Hutchins AM \& Slavin JL (1998) Urinary equol excretion with a soy challenge: influence of habitual diet. Proc Soc Exp Biol Med 217, 335-339.

36. Bond JH, Engel RR \& Levitt MD (1971) Factors influencing pulmonary methane excretion in man. $J$ Exp Med 133, 572-588.

37. Miller TL \& Wolin MJ (1986) Methanogens in human and animal intestinal tracts. Syst Appl Microbiol 7(2-3), 223-229.

38. Fernandes J, Wolever TMS \& Rao AV (2000) Interrelationships between age, total dietary fiber intake and breath methane in humans. Nutr Res 20, 929-940.

39. Calloway DH, Colasito DJ \& Mathews RD (1966) Gases produced by human intestinal microflora. Nature 212, 1238-1239.

40. Frankenfeld CL, Atkinson C, Thomas WK, Goode EL, Gonzalez A, Jokela T, Wähälä K, Schwartz SM, Li SS \& Lampe JW (2004) Familial correlations, segregation analysis, and nongenetic correlates of soy isoflavone-metabolizing phenotypes. Exp Biol Med 229, 902-913.

41. LeMarchand L, Franke AA, Custer LJ, Wilkens LR \& Cooney RV (1997) Lifestyle and nutritional correlates of cytochrome CYP1A2 activity: inverse associations with plasma lutein and alpha-tocopherol. Pharmacogenetics 7, 11-19. 
42. Rizzo N, Hispard E, Dolbeault S, Dally S, Leverge R \& Girre C (1997) Impact of long-term ethanol consumption on CYP1A2 activity. Clin Pharmacol Ther 62, 505-509.

43. Higdon JV \& Frei B (2006) Coffee and health: a review of recent human research. Crit Rev Food Sci Nutr 46, 101-123.

44. Gates S \& Miners O (1999) Cytochrome P450 isoform selectivity in human hepatic theobromine metabolism. J Clin Pharmacol 47, 299-305.

45. Lampe JW, Skor HE, Wähälä K, Howald WN \& Chen C (2001) Wheat bran and soy protein feeding do not alter urinary excretion of the isoflavan equol in premenopausal women. J Nutr 131, 740-744.

46. Vedrine N, Mathey J, Morand C, Brandolini M, Davicco MJ, Guy L, Remesy C, Coxam V \& Manach C (2006) One-month exposure to soy isoflavones did not induce the ability to produce equol in postmenopausal women. Eur J Clin Nutr 60, 1039-1045.
47. Batterham TJ, Shutt DA, Hart NK, Braden AWH \& Tweeddale HJ (1971) Metabolism of intraruminally administered [4- $\left.{ }^{14} \mathrm{C}\right]$ formononetin and $\left[4-{ }^{14} \mathrm{C}\right]$ biochanin $\mathrm{A}$ in sheep. Aust $J$ Agric Res 22, 131-138.

48. Lundh TJO, Pettersen H \& Kiessling K (1988) Demethylation and conjugation of formononetin and daidzein in sheep and cow liver microsomes. J Agric Food Chem 36, 22-25.

49. Schmider J, Greenblatt DJ, Von Moltke LL, Karsov D, Vena R, Friedman HL \& Shader RI (1997) Biotransformation of mestranol to ethinyl estradiol in vitro: the role of cytochrome P-450 2C9 and metabolic inhibitors. J Clin Pharmacol 37, 193-200.

50. Milligan SR, Kalita JC, Pocock V, Heyerick A, De Cooman L, Rong H \& De Keukeleire D (2002) Oestrogenic activity of the hop phyto-oestrogen, 8-prenylnaringenin. Reproduction 123, $235-242$. 